\title{
A Fuzzy Model for Estimating Accidents Possibility of Occurrence in the Construction Industry
}

\section{Abel Pinto* \\ Industrial Engineering, New University of Lisbon, Portugal}

*Corresponding author: Abel Pinto, Industrial Engineering, New University of Lisbon, Avenida do Mar 30 5Esq 2825-476 Costa da Caparica, Portugal,

Tel: 351 966870405; Email: abel.fnpinto@gmail.com

\section{Review Article \\ Volume 3 Issue 3}

Received Date: March 28, 2019

Published Date: May 07, 2019

DOI: $10.23880 /$ eoij-16000204

\section{Abstract}

Quantify or, more generally, estimate the possibility of occurrence of occupational accidents is a decisive step in any occupational risk assessment process. Due to the lack of historic information in the construction industry (accident data collection and recording are incipient and insufficient) and the lack of practical and acurate tools to estimate/quantify the risks of occuring work accidents we need a more systematic and rigorous approach for the construction industry.

This work purpose is the definition of a practical Ocuppational Accidents Possibility of occurrence (OAP) model, which proposes a fuzzy approach to determine the posssibility of occurrence of accidents modes. The OAP includes 4 main steps: (1) identification of accidents'modes; (2) definition of a checklist with questions related to factors that may affect the accidents possibility; (3) assessment (rating) of each factor using a fuzzy linguistic variable "adequacy"; (4) aggregation of the rated factors per each mode of accident. The factors will be evaluated by safety experts, from observable conditions or existing data on the construction site. The proposed fuzzy rating evaluation process is done with a linguistic variable that allows measuring the level of inadequacy of the factors. We believe our proposed OAP model contributes to advances in determining the quality of the overall occupational risk assessment.

Keywords: Possible Accidents; Occupational Safety Risk Assessment; Fuzzy Sets

\section{Introduction}

In the general occupational safety risk assessment (OSRA) methods the possibility of ocurrence of work accidents is a component of the estimation of the overall occupational risk. The notion of work accident ocurrence possiblity seems very clear and extremely useful for understanding occupational risks and hence mitigated them. But, as soon as one delves deeper into specific cases, it transpires that the concept application becomes a complex task. Complexity derives from the multiplicity of possible combinations of precursors and immediate factors for a given accident mode, due to the diversity of equipments, materials, workers personal characteristics (age, training, experience, etc..), work organization, organization safety culture, leadership, etc.

Phimister, et al. [1] and $\mathrm{Wu}$, et al. [2] defined precursor as the signs that always seem to precede the accidents caused by occupational safety hazard on construction sites and immediate factors as the failure in the interaction between the work team, workplace, 


\section{Ergonomics International Journal}

equipment and materials, which are important exacerbating factors of accidents on construction sites. Differences between precursors and immediate factors lie essentially on time constraints. Immediate factors always have a short period for taking preventive actions, while percursors allow taking early preventive measures [1]. Precursors are a widely range, consist not only in the factors of worker, environment, equipment and material respectively, but also in their mutual interactions. In the present work, precursors and immediate factors, hereafter will be called factors, because our objective is to analyze and measure factors which contribute to the possibility of work accidents ocurrence on construction sites, regardless of their type.

Several other models of the causative factors of occupational accidents have been proposed [3-7]. Particularly, Sawacha, et al. [3] analyzed the factors influencing safety on construction sites including historical, economic, psychological, technical, procedural, organizational and environmental issues. However, are based on analyst subjective judgments that often influence their accuracy. Safety Climate factors are out of that paper scope because the subject is developed in another paper of the same authors.

However, in this work we will focus on factors affecting eight identifyed types of accidents, which constitute the most commonly occuring in the construction industry. Usualy, on construction industry, assessing the accidents'occurrence possibility from a variety of factors, can lead to widely different conclusions, due to the intrinsic subjectivity of evaluations, since it depends largely on the analyst estimations and perceptions. The underlying complexity of the task poses the problem: it is possible to accuratly measure the possibility of occurrence of occupational accidents?

A model for "measuring" the degree of possibility of potentially hazardous events occurrence would be of undeniable value to organisations seeking to improve their understanding of the complexity of such events. Possibility measurement implies the determination, based on the adequacy of several factors, of a quantitative method. Moreover, since accidents possiblity derive from highly variable set of factors, then, in practice, this is rather a difficult problem to tackle.

The Ocuppational Accidents Possibility of occurrence (OAP) model is based on 4 steps (Figure 1). First the main interveening factors are identified (first step). Then (step 2) an extensive checklist of relevant questions for eight different types of accidents is devised.. After, we propose to use a linguistic variable "Adequacy" to rate how safe the factors are considered by the safety experts (step 3 of OAP). Then, we use a specialized fuzzy operator to determine an overall measure for each class of factors regarding the possibility of occurrence of occupational accidents in any construction site (step 4 of OAP).

The final result of this work is a versatile and systematic Ocupational Accidents Possibility model, capable of handling uncertainty and displaying a user-friendly assessment method.

\section{OAP Background}

To understand the probability of an undesired event, it is required, first of all, to define the experiment and the corresponding sample space (in terms of the underlying axiomatic theory [8]. Moreover, as probabilities are not directly available (except in basic experiments when all outcomes are of equal probability), they must be estimated for each of the outcomes [9]. This can be done by different ways ranging from subjective probabilities (derived solely from individual judgment), to probabilities based on a series of observations, or frequency probabilities (structural properties may also lead to specific attribution in experiments governed by the laws of physics).

However, in imprecise contexts, such as occupational risks, the precise definition of an experiment and respective sample space raises problems of duration, work variability, human variability and generalization of the conditions in question. Any risk assessment based on a series of observations should involve a critical assessment of the realism of these two requirements: do the observations concern the same random experiment, and are they independent [9].

Our answer to both questions is "no" because in occupational risk world, vagueness and ambiguity exist due to the limitations of our language and other factors such as context and subjective evaluations. By definition, OSRA deals with uncertain situations, that is, with situations in which we do not have complete and accurate knowledge about the state of the system, and where it is rather difficult to estimate work accidents ocurrence possiblity. Moreover, the nature of work in construction sites is plagued with imprecisions. On-site inspections generally use linguistic expressions rather than metrics to assess the safety risks. Additionally, legal records, statistical data and site documentation produced by companies are generally insufficient for determining the 


\section{Ergonomics International Journal}

associated risks. These facts increase the imprecision/uncertainty of the job site environment.

Fuzzy Set Theory (FST) was formulated, in 1965, by Lotfi Zadeh [10]. FST provides a mathematical framework for the systematic treatment of vagueness and imprecision. More specifically, FST may be viewed as an attempt at formalizing two remarkable human capabilities [11]: 1) to converse, reason and make rational decisions in uncertain environments; and 2) to perform a wide variety of physical and mental tasks without any quantitative measurement.

A fuzzy set is said to include a boundary with a gradual contour, by contrast with classical sets, which present a discrete border, i.e. either belongs or not to a set. Formally, let $\mathrm{U}$ be the universe of discourse and $u$ a generic element of $U$, a fuzzy subset $A$, defined in $U$, is one set of the dual pairs:

$A=\left\{\left(u, \mu_{A}(u)\right) \mid u \in U\right\}(1)$

where $\mu_{A}(u)$ is designated as membership function or membership grade of $u$ in $A$. The membership function associates to each element $u$, of $U$, a real number $\mu_{A}(u)$, in the interval $[0,1]$, where 0 means that it does not belong to the set and 1 means it "strongly" belongs, while intermediate values mean different degrees of "belonginess"

An important concept in FST is the linguistic variable [12-14]. A linguistic variable is a variable that admits a set of labels (terms) of a natural language, each represented by a fuzzy set. An example is "temperature" that can be represented by the labels (cold, average-temperature, warm) and each label will then be represented by a fuzzy set.

It should also be pointed that FST deals with possible events and not with probable events. Possibility is the degree with which a variable may take a value and describes whether an outcome may happen while probability describes whether it will happen [15]. Hence, probability theory does not get displaced by FST, the two approaches are complementary. Probability theory is good for crisp but dispersed information, whereas FST is good for fuzzy but coherent information [15].

In summary, probabilistic risk assessments approaches, have been widely utilized but they may be difficult to use under circumstances where there is a lack of information about past experience, or in ill-defined situations. In construction sites, vague terms are unavoidable, since safety professionals often assess risks in qualitative linguistic terms. Under these circumstances, probabilistic approaches may not be able to model safety for the whole construction process as effectively and efficiently as FST. These are the motivations for our choice of framework.

\section{Occupational Accidents Possibility (OAP) Model}

Our model development began with a literature survey of previous work. During the research it became evident that there was no quantitative method that was simultaneously, accurate and practical. Hence we propose to follow a four-step approach in our OAP model:

- Step 1 - Identification of accident modes for occupational accident scenarios;

- Step 2 - Identification of factors affecting the possibility of each accident mode, and creation of check-lists thatexpressing the relations between occupational accident scenarios and possibility factors.

- $\quad$ Step 3 - Rating of factors using a fuzzy linguistic variable "adequacy".

- Step 4 - Final evaluation of the possibility of occurrence of accidents in a construction site by using a specialized aggregation operator (fuzzy-or).

Graphically, the OAP model is depicted in Figure 1.

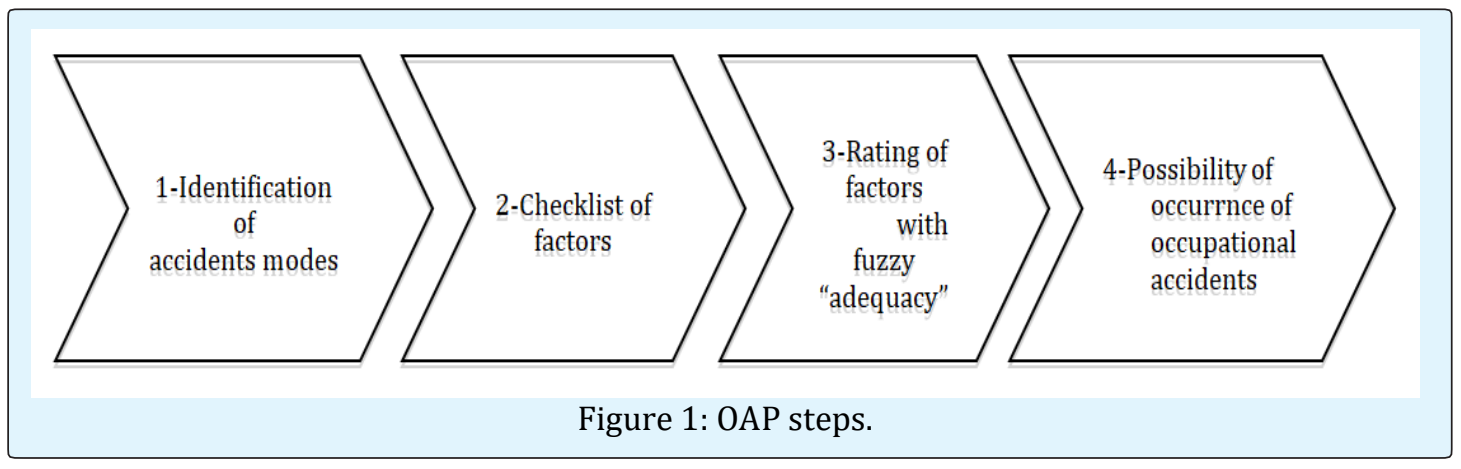

Abel Pinto. A Fuzzy Model for Estimating Accidents Possibility of Occurrence in the Construction Industry. Ergonomics Int J 2019, 3(3): 000204. 


\section{Ergonomics International Journal}

\section{Step 1: Identification of Accident Modes}

To fulfill this step we combined the proposals from some authors [16,17]. The types of accidents to be considered in our model are:

- Falls (general) ;

- Contact with electricity;

- Struck by moving vehicle (including heavy equipment);

- Injured by falling/dropped/collapsing object/person/wall/vehicle/crane which is falling under gravity (including building/structure collapse);

- Cave-ins;

- Hit by rolling/sliding object or person (include awkward or sudden movement);

- Contact with machinery moving parts (including injured by hand held tools operated by self);

- Lost buoyancy in water or other liquid in which the person is in due to the activity;

- Fire or Explosion.

The required data for assessing each accident mode must be derived from: a) analysts direct observation and assessement of possiblity accident factors and b) analysis of the details of the factors.

\section{Step 2: Elicitation Process using Questionnaire for OAP Rating}

Each accident mode may be caused by a specific set of factors. The extent to which these factors represent the evaluation of the work situation, under analysis, determine the greater or lesser possibility of occuring work accidents.

The considered factors were obtained from the MOSH Checklist for Self-Inspection [18] and also from empirical experts knowledge. In the next sub-sections we present the prepared checklist of questions with the identified factors, that will serve as the basis for the factor's evaluation and respective rating. Each question of the chacklist will be answered by the sfety expert using the linguistic variable "Adequacy" (Table 1) to express how adequate each factor is. I.e. the sagfety expert will rate each question using one of the five terms (Table 1) from strongly adequate,to inadequate.
Questionnaire about factors affecting falls (F): The rating to the following questions allow to assess the factors that contribute to the possibility of work accidents by fall, including falls on the same level and numerous types of falls from heights (from ladders, roofs, moveable platforms etc).

\section{General}

- To what extent the work was properly planned to be carried out in a safe way (especially work on or near fragile roof surfaces, erecting/ dismantling / altering scaffolding)?

- To what extent are fragile surfaces (e.g. asbestos cement sheet, plastic sheet, corroded metal sheet, glass, wood, roof lights, bridged materials in silos, crusted surfaces of sludge lagoons) been identified?

- To what extent are floor openings properly protected?

- To what extent are means of access to work places at height adequate?

- To what extent are fixed stairs provided with protection against falling from either side (e.g. robust handrails)?

- To what extent are fixed stairs appropriate and kept in good condition (ie not too steep and not too narrow, without: slippery floors, worn floor, not uniform floor, steps with not uniform heights, handrails loose or weak...)?

- To what extent are skylight openings guarded by fixed standard railings on all exposed sides or are covers capable of supporting $100 \mathrm{~kg}$ installed?

- To what extent are wall openings with $1.20 \mathrm{~m}$ or more above ground properly guarded?

- To what extent are extension platforms outside a wall properly guarded with side rails or equivalent guards?

- To what extent are the standard railings used and installed properly for open sided floors platforms with $1.20 \mathrm{~m}$ or more above ground or floor levels?

- To what extent are flights of stairs with four or more risers equipped with standard stair railings or handrails?

- To what extent proper measures are taken so that employees working on roofs at a height greater than $1.20 \mathrm{~m}$ protected from falling from he roof?

- To what extent are employees working in a roof edge, materials handling area or materials storage area 


\section{Ergonomics International Journal}

protected properly from falling by guardrails, safety nets, or a safety belt system?

- To what extent are stairways, runways and wall opening areas well illuminated?

- To what extent are lighting levels adequate (functioning and position of lights to ensure all floor areas are evenly lit and all potential hazards, e.g. obstructions and spills can be clearly seen)?

- To what extent is the working environment clean and tidy, with floors and access routes kept clear of obstacles?

\section{Scaffolds}

- Are all workers involved in the erection, alterationand dismantling of scaffolds competent to performe the task?

- To what extent are scaffold secured to the building or structure in enough places to prevent collapse?

- To what extent is the access to the platforms done through the interior of the scaffolds?

- To what extent mobile scaffold wheels have a braking system (kept in good condition) that prevents their uncontrolled movement?

- To what extent mobile scaffold wheels are adequate (diameter greater than or equal to $15 \mathrm{~cm}$ ) and respect the stability condition (height/width at least 3.5)?

- To what extent are suspended scaffold adequate (in EU countries must bear the "CE" mark) are regularly inspected and keep in good condition?

- To what extent is forbidden to work in suspended scaffolds with winds exceeding $40 \mathrm{~km} / \mathrm{h}$ )?

- To what extent is forbidden a single worker to work in suspended scaffolds?

- To what extent is complied with the maximum permissible load (in any hind of scaffold)?

- To what extent are aisles and passageways kept clear and in good condition?

- To what extent is form and scrap lumber with protruding nails and all other debris kept cleared from work areas, passageways, and stairs?

\section{Portable Ladders}

- To what extent are portable ladders placed correctly, at an angle of one in four, (one unit of measurement out for every four units up), on and against a material that has a reasonable coefficient of friction and strength?

- To what extent are portable ladders equiped with stability devices or tied (or equally effectively secured against movemen) at the top?

- To what extent are ladders with broken or missing rungs or split side rails, tagged and taken out of service?

- To what extent are metal ladders inspected for damage or signs of corrosion?

- To what extent are portable ladders used only in short-term jobs (not exceeding $30 \mathrm{~min}$ and do not require the worker side loads)?

- To what extent are portable wood ladders adequate for their purpose, in good condition, and provided with secure footing (rungs of ladders uniformly spaced and not exceeding $30 \mathrm{~cm}$ )?

- To what extent are areas around the top and bottom of the portable ladder kept clear?

- To what extent are portable ladders prohibited from being used in a horizontal position as platforms, runways, or scaffolds?

- To what extent are the side rails of the portable ladder extending above the landing (at least $90 \mathrm{~cm}$ )?

- To what extent are the distance at the base of the open portable ladders $15 \mathrm{~cm}$ by each $30 \mathrm{~cm}$ in high?

Questionnaire about factors affecting contact with electricity (E): The answers to the following questions allow to assess the factors that contribute to the possibility of work accidents by contact with electricity.

a) To what extent the work was properly planned, appropriately supervised, and carried out in a safe way?

b) To what extent are electrical equipments (cables, frames, accessories) revised before being reassembled in a new site?

c) To what extent does electrical equipment meet all the legal or normative requirements?

d) To what extent are all electrical cords or cables taken out of service when worn or frayed?

e) To what extent are aerial lift equipments working near energized lines or equipment grounded or barricaded properly and considered as energized equipment or the truck insulated for the work being performed? 


\section{Ergonomics International Journal}

f) To what extent is all electrical equipment free from recognized hazards (insulation defects, eg) that may cause death or serious harm?

g) To what extent are live electrical parts properly guarded against accidental contact?

h) To what extent are safety distances to the electric network ( $2 \mathrm{~m}$ until $1 \mathrm{kV}, 4 \mathrm{~m}$ between $1 \mathrm{kV}$ and $60 \mathrm{kV}$, $5 \mathrm{~m}$ to over $60 \mathrm{kV}$ ) met?

i) To what extent are ground fault circuit interrupters properly used to protect employees?

j) To what extent are all outlet devices correctly and properly matched with load being served?

k) To what extent is the path to ground from circuits, equipment, and enclosures satisfied so that they are permanent and continuous?

l) To what extent are all the electrical extension cords of the three wire type (with ground wire, green wire and yellow wire)?

m) To what extent is the protection of the lamps for general illumination against breakage proper and satisfactory?

n) To what extent are the protection measures for flexible cords and cables satisfactory against damage?

o) To what extent are all cabinets, cut out boxes, fittings, boxes, panel board enclosures, switches, circuit breakers, through doorways or windows, attached to building surfaces, or concealed behind walls, ceilings, or floors?

p) To what extent all pull boxes, junction boxes, and fittings have covers?

q) To what extent are all electrical equipment used in hazardous locations intrinsically safe?

r) To what extent are electric powered tools doubleinsulated or properly grounded?

s) To what extent are deenergization tests or other appropriate methods or means applied so that the electric equipment and lines are considered deenergized?

t) To what extent workers don't wear metal objects (rings, watches...) when working with electrical devices?

u) To what extent are the measures taken so that electrodes removed and electrode holders placed or protected cannot make electrical contact with employees when the holders are left unattended? v) To what extent are all disconnecting devices legibly marked to indicate purpose unless located so that purpose is evident?

w) To what extent metal ladders are not used when working on or near electrical equipment (such as changing light bulbs or fluorescent tubes)?

$\mathrm{x}$ ) To what extent is electric power operation tools equipment with proper ground or double insulated?

y) To what extent is sufficient working space provided to permit safe operation and maintenance of electrical equipment?

Questionnaire about factors affecting Struck by Moving Vehicle (S) The answers to the following checklist allow to assess the factors that contribute to the possibility of work accidents by struck by moving vehicle.

a) To what extent are established a traffic plan for the site (with separate pedestrian, vehicle access points and routes around the site been, if not, are vehicles and pedestrians kept separate wherever possible)?

b) To what extent are ensured that all visiting drivers report to site management before entering the site (to assure that drivers had received proper safety training)?

c) To what extent are one-way systems or turning points been provided to minimise the need for reversing?

d) Where vehicles have to reverse, to what extent are there a trained signaller to assist the vehicle driver?

e) To what extent are vehicles maintained? do the steering, handbrake and footbrake work properly?

f) To what extent are check that vehicle traffic routes are suitable for the types and quantity of vehicles that use them. (ensure they are wide enough and that floor and road surfaces are kept in good condition)?

g) To what extent are obstructions removed where possible, otherwise, make sure they are clearly visible (avoid including sharp bends in road layouts. Provide suitable fixed mirrors at blind corners)?

h) To what extent are check that suitable safety features (Direction, speed limit and priority signs.are provided.)?

i) To what extent physical speed restrictions such as speed bumps are taked (if necessary)?

j) To what extent are vehicles securely loaded and without overload? 


\section{Ergonomics International Journal}

k) To what extent are passengers prevented from riding in dangerous positions?

1) To what extent are flagmen wears proper (red or orange warning garments) or for working at night are reflectorized wearing garments satisfactory?

m) To what extent are there proper warning vests made of reflectorized or high visibility material and to what extent are they being used by employees exposed to vehicular traffic?

n) To what extent are parking brakes set on for all parked motor vehicle, and are necessary measures taken when vehicles parked on an incline? (for example, are wheels chocked for all equipments)?

o) To what extent are do all vehicles with an obstructed view to the rear have a back up alarm or are always used with an observer?

p) To what extent are vehicles in use inspected at the beginning of each shift to assure that all parts, equipment, and accessories affecting safety operation are free of defects?

q) To what extent traffic or warning signs are satisfactory?

r) To what extent are provided supportive structures where necessary to prevent collapse and to prevent vehicles running of the roadway?

s) To what extent near roads, delimitation and signalization is made with retroreflective material?

Questionnaire about factors affecting injured by falling objects (Fo): The answers to the following checklist allow to assess the factors that contribute to the possibility of work accidents by injured by falling objects, including persons, dropped or collapsing objects, wall, vehicle, crane, etc

a) To what extent the work was properly planned, appropriately supervised, and carried out in a safe way?

b) To what extent are materials which are stored in tiers either stacked, racked, blocked, interlocked, or otherwise properly secured to prevent sliding, falling, or collapse?

c) To what extent is known the weight of the loads to move (if is not known it is estimated by multiplying the load volume by the material specific weight)?

d) To what extent is the storage of materials properly done (are materials stored more than 1,80 m from any hoist way or inside floor opening and more than 3 $\mathrm{m}$ from any exterior walls that do not extend above the top of the stored materials)?

e) To what extent are accessible areas within the swing radius of the rotating superstructure of the crane properly barricaded or protected?

f) Where conveyors pass over areas or aisles, to what extent have proper guards been provided to protect employees from falling materials?

g) To what extent are all floor openings not used as material drops equipped with a properly secured cover that will support any load which may be imposed?

h) To what extent is any area where material is dropped outside the exterior walls of the structure effectively and properly protected?

i) To what extent are all formworks for cast-in-place concrete designed, fabricated, erected, supported, braced, and maintained so that it will support without failure all loads that may be anticipated?

j) To what extent is inspection of the erected shoring equipment performed (is inspected immediately prior to, during and immediately after concrete placement properly satisfied)?

k) To what extent is the inspection of the forms and shores performed properly, so that the forms and shores left in place until employer determines that the concrete can support its weight and superimposed loads?

1) To what extent are precast concrete wall units, structural framing, and tiltup wall panels supported properly to prevent overturning and collapse until permanent connections are made?

m) To what extent do designs and plans include prescribed methods of erection?

n) To what extent are the jacking operations performed properly (For example are jacking operations synchronized to insure even and uniform lifting)?

o) Are only those employees required for jacking and to secure slabs permitted under slab during jacking?

p) When constructing a masonry wall, to what extent are is a limited access zone established securely?

q) To what extent are proper conditions satisfied for all masonry walls over eight feet in height (are they braced or supported properly to prevent collapse)?

r) To what extent are inspections made by a competent person as work progresses to detect hazards from 


\section{Ergonomics International Journal}

weakened or deteriorated floors or walls or loosened materials?

s) To what extent are do any hooks, rings, oblong links, pearshaped links, coupling links, and other attachments have a rated capacity at least that of the chain?

t) To what extent areraised loads kept as close to the ground as possible to prevent tipping while traveling?

u) To what extent are Mobile Elevating Working Platforms (MEWP'S) provided with guard rails, toeboards, stability devices (e.g. outriggers, locking-out controls (other than those in the basket) to prevent inadvertent operation?

v) To what extent are MEWP'S used on firm ground which is free from slopes / holes andthe work area checked for localised features, eg manholes, service ducts, potholes, etc (eg a hole $75 \mathrm{~mm}$ deep caused an overturn).)?

w) To what extent are checked for overhead crushing or contact hazards?

$\mathrm{x}$ ) To what extent are there systems of communication between operators and banksman?

y) To what extent are weather conditions checked and established limits for safe operation (eg maximum wind speed $40 \mathrm{~km} / \mathrm{h})$ ?

z) To what extent are stabilisers/outriggers be provided with suitable soleplates for use on soft ground?

aa) To what extent all scaffolds have footers?

Questionnaire about factors affecting cave-ins (Ci): The answers to the following check-list allow to assess the factors that contribute to the possibility of work accidents by cave-ins (either extension or ditch).

a) To what extent are ensured that the work was properly planned, appropriately supervised, and carried out in a safe way as is reasonably practicable?

b) To what extent the excavation area is properly demarcated and signlized?

c) To what extent are all excavations slop to at least the angle of respose except for areaswhere solid rock allows for line drilling or presplitting?

d) To what extent are all structures become unstable by excavation works (walls, trees, poles...) were properly anchored?

e) To what extent are all surface encumbrances that may create a hazard removed or supported? f) To what extent is proper warning system such as barricades, hand or mechanical signals or stop logs used when mobile equipment approaches the edge of the excavation?

g) To what extent are excavation or other materials kept at least $1 \mathrm{~m}$ from the edge of excavations?

h) To what extent daily inspections made of the excavation to determine the possibility of cave-in and are necessary steps taken to protect employees?

i) To what extent are excavations inspected and is it inspected after any hazard increasing occurrence?

j) To what extent are shoring or sloping systems used to support the walls and faces of the excavations sufficient to ensure against cave-ins?

k) To what extent there are ladders placed among in the excavation?

1) To what extent near roads, vehicules speed was properly reduced (to reduce vibration)?

m) To what extent on the sidewalks was assured pedestrians safety by outlining the obstacles and/or forcing pedestrians to walk in the opposite side?

Questionnaire about factors affecting hit by rolling/sliding object or person (include awkward or sudden movement) (H): The answers to the following check-list allow to assess the factors that contribute to the possibility of work accidents by hit by rolling/sliding object or person (include awkward or sudden movement).

a) To what extent are abrasive wheel grinders provided with safety guards which cover the spindle ends, nut and flange projections?

b) To what extent are ensured that workers receive adequate information on the weight of a load, the centre of gravity or the heaviest side when a package is unevenly loaded?

c) To what extent are material and equipment that might fall or roll into an excavation keep at least 2 meters from the edge?

d) To what extent are any vehicle left without being properly locked?

e) To what extent are work areas well lit, dry and clean?

f) To what extent are observers keep at a safe distance from work equipments?

g) To what extent are all vehicles which are left unattended at night, adjacent to a highway in normal 


\section{Ergonomics International Journal}

use or a construction site where work is in progress, equipped with lights, reflectors, or barricades to identify the location of the equipment?

h) To what extent are vehicles securely loaded (ensuring that the cargo is stowed and not beyond the loading box)?

i) To what extent is strictly forbidden to throw tools or other objects?

Questionnaire about factors affecting contact with machinery moving parts (M): The answers to the following check-list allow to assess the factors that contribute to the possibility of work accidents by contact with machinery moving parts.

a) To what extent do all circular saws have an exhaust hood or a guard to prevent accidental contact with the saw blade)?

b) To what extent do all portable circular saws have a guard above the base plate and a guard below the base plate that will automatically and instantly return to the covering position when the saw is withdrawn from the work?

c) To what extent are rotating or moving parts of equipment guarded to prevent contact by employees?

d) To what extent are machinery guards kept in place and in working order?

e) To what extentare saw guards checked to assure they are not wedged up thereby leaving an unguarded lower portion of the blade?

f) To what extent are work rests and tongue guards properly set?

g) To what extent are hand tools and other equipment regularly inspected for safe condition (including visual inspection each day for defects or obstructions prior to use)?

h) To what extent are tool handles free of splits and cracks?

i) To what extent are handles wedged tightly in the heads of all tools?

j) To what extent are impact tools free of mushroomed heads?

k) To what extent are the heads of chisels or punches ground periodically to prevent mushrooming?

1) To what extent are frames of all arc welding and cutting machines grounded properly? m) To what extent are welding and cutting operations shielded by non combustible or flameproof screen whenever practicable?

n) To what extent are all employees who are performing any type of welding, cutting, or heating protected by suitable eye protective equipment?

o) To what extent are power tools, belts, gears, shaft, pulleys, sprockets, spindles, drums, fly wheels, and chains properly guarded?

p) To what extent are portable circular saws equipped with guards above and below the base or shoe?

q) To what extent are power saws and similar equipment provided with safety guards?

r) To what extent are tools used with the correct shield, guard, or attachments recommended by the manufacturer?

s) To what extent are powder actuated tools left unloaded until they are ready for immediate use?

t) To what extent are tools stored in a dry, secure location where they won't be tampered with?

u) To what extent are gears on the hoisting machine well guarded?

Questionnaire about factors affecting fire or explosion (FE): The answers to the following check-list allow assessing the factors that contribute to the possibility of work accidents by fire or explosion.

a) To what extent are all flammable and combustible liquids stored and handled in approved and proper containers and portable tanks?

b) To what extent flammable, combustible and explosives are stored in an appropriated conditions?

c) To what extent are explosives not in use kept in a locked magazine?

d) To what extent are necessary safety conditions satisfied for motor vehicles transporting explosives (are they always attended)?

e) To what extent are smoking, firearms, matches, open flame lamps and other fires, flame or heat producing devices, and sparks prohibited in or near flammables and explosive magazines and while flammables or explosives are being handled, transported, or used?

f) To what extent are oxygen cylinders and fittings kept away from oil and grease? 
g) To what extent are are cylinders secured (and caps in place) when transporting or storing compressed gas cylinders?

h) To what extent are all compressed gas cylinders secured in an upright position at all times (including when transported by power vehicles)?

i) To what extent are insured that cylinders, full or empty, are never used as rollers or supports?

j) To what extent are torches inspected for leaking shut off valves, hose couplings, and tip connections at the beginning of each shift?

k) To what extent have mechanical ventilation system sufficient capacity and so arranged to remove fumes and smoke and keep the concentration within safe limits?

l) To what extent are drums, containers, or hollow structures which have contained toxic or flammable substances either filled with water or thoroughly cleaned of such substances, ventilated and tested before welding, cutting, or heating?

\section{Step 3: Rating factors with Linguistic Variable "Adequacy"}

To determine the greater or lesser possibility of each factor to contribute to the occurrence of a type (mode) of work accident we build the linguistic variable "Adequacy" (Figure 2). This linguistic variable enable us to evaluate each factor, assuming six semantic terms that are represented by triangular membership functions in the interval $[0,1]$, as shown in Figure 2. The 6 terms will allow a more user-friendly elicitation of knowledge bacause the checklists are answered semantically as: (a) "strongly adequate", range [0.8, 1.0]; (b) "very adequate", range [0.6, 1.0]; (c) "adequate", range [0.4, 0.8]; (d) "almost adequate", range $[0.2,0.6]$; (e) "low adequate", range [0.0, 0.4]; (f) and "inadequate", range $[0.0,0.2]$.

In step 3 of OAP the factors are assessed with the semantic terms (user-friendly for evaluators) and in the background the OAP (step 4) perfoms the calculations for each accident mode to obtain the respective possibility of occurrence. For example, if the traffic plan for the site has pedestrian, vehicle access points and routes full separated, it is "strongly adequate"; if in some points, like access points, there is no separation but there are flagmen it is "very adequate"; if in some points, like access points, there is no separation but there are traffic lights it is "adequate"; if in some points, like access points, there is no separation but there is good visibility it is "almost adequate"; if in some points, like access points, there is no separation, there is no visibility and no measures to prevent strucking by moving vehicle it is "low adequate"; if there is no traffic plan for the site and movements of people and vehicles are chaotic it is "inadequate".

To simplify the rating and calculation process (step 3 and 4) we used the conversion method proposed by Cheng and Hwang (1992), to discretize the fuzzy terms of the linguistic variable "Adequacy". Information loss resulting from the discretization will not significantly affect the evaluation result as shown in the interestinh application of Simões-Marques [19]. This discretization process is as follows.

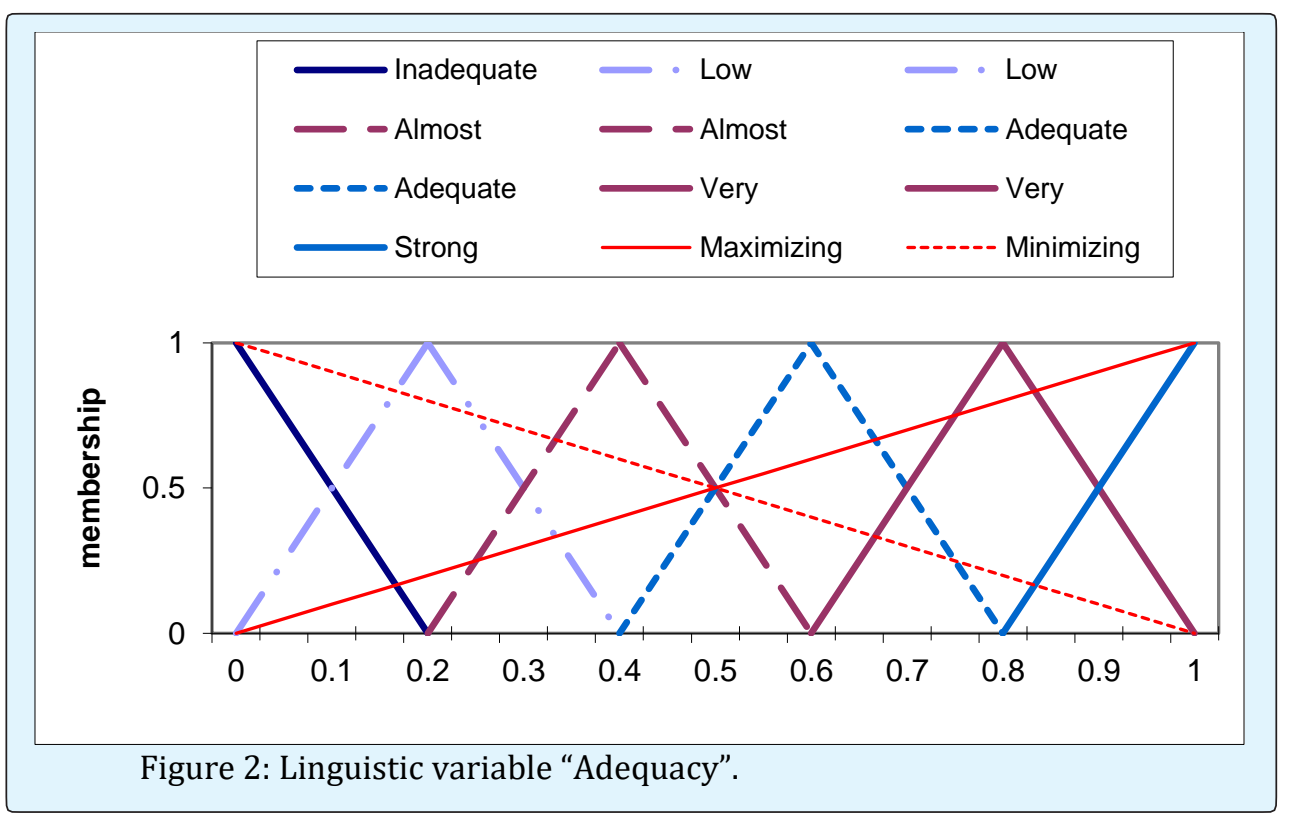

Abel Pinto. A Fuzzy Model for Estimating Accidents Possibility of Occurrence in the Construction Industry. Ergonomics Int J 2019, 3(3): 000204. 
First, we start by considering two fuzzy linear functions, a maximizing one $\max _{(x)}$ (see red line on figure) and a minimizing one $\min _{\text {in }}(x)$ (see red dotted line on figure).

Second, we determine the values of the intersection of the left side of each linguistic term with the minimizer and the right side of each linguistic variable term with the maximizer, such as:

$$
\begin{aligned}
& \mu_{E}(A)=\sup _{x}\left[\mu_{A}(x) \wedge \mu_{\min }(x)\right](2) \text { and } \\
& \mu_{D}(A)=\sup _{x}\left[\mu_{A}(x) \wedge \mu_{\max }(x)\right] \text { (3) }
\end{aligned}
$$

And, finally, the membership grade for each linguistic term (T) is obtained through the expression:

$$
\mu_{T}(A)=\left[\mu_{D}(A)+1-\mu_{E}(A)\right] / 2(4)
$$

In addition, since we want to measure the possibility of occurrence of accident'modes, when a site is "inadequate" it means the risk of accident is high, hence we use the inverse values to express how the factors affect negatively the possibility of occurrence (e.g. "low adequacy" means "high" possibility of occurrence, hence its membership value is 0.79 ).

From these calculations, the set of discrete terms that will be used in the linguistic variable "Adequacy" is shown in Table 1.

\begin{tabular}{|c|c|c|}
\hline $\begin{array}{c}\text { Semantic } \\
\text { term }\end{array}$ & Meaning & $\begin{array}{c}\text { Membership } \\
\text { grade (1- }{ }_{T} \text { ) }\end{array}$ \\
\hline $\begin{array}{c}\text { Strongly } \\
\text { adequate }\end{array}$ & $\begin{array}{c}\text { All the existing possible factors are controlled by existing effective and reliable } \\
\text { preventive measures (best practices and/or other relevant conditions apply). }\end{array}$ & $\mathbf{0 . 0 6}$ \\
\hline Very adequate & (All the existing .....), but reliability can be improved. & $\mathbf{0 . 2 1}$ \\
\hline Adequate & (All the existing....) but reliability need be improved. & $\mathbf{0 . 4 1}$ \\
\hline $\begin{array}{c}\text { Almost } \\
\text { adequate }\end{array}$ & $\begin{array}{c}\text { Some of the existing possible factors are not well controlled. Accidents can } \\
\text { occur. Preventive Measures can be improved. }\end{array}$ & $\mathbf{0 . 5 6}$ \\
\hline $\begin{array}{c}\text { Low adequate } \\
\text { to occur. Preventive measures exist but are not effective. }\end{array}$ & $\begin{array}{c}\text { Some of the existing possibility factors are not controlled. Accidents are likely } \\
\text { Inadequate }\end{array}$ & $\begin{array}{c}\text { Some of the existing possible factors are out of control. Accidents are likely to } \\
\text { occur frequently. Continuously experienced. No Preventive Measures. }\end{array}$ \\
\hline
\end{tabular}

Table 1: Linguistic variable "Adequacy" for accident's influencing factors.

Since we use the inverse membership values we are able to obtain a kind of "direct" measure for the possibility of accidents ocurence, where 0 corresponds to the impossibility of occuring accidents (i.e. the factors are strongly adequate) and 1 corresponds to high possibility of occurrence (i.e. factors are inadequate). In this fashion, we are able to convey the logic of considering that "strongly adequate" implies very low (0.06) possibility of occuring accidents. Conversely, inadequate factores (inadequate $=0.94$ ) are the ones that most contribute to the accident ocurence possibility.

\section{Step 4: Evaluation of Possibility of Occurrence of Occupational Accident'S}

Aggregation operations allow the combination of membership values to obtain a final rating. It can also combine several fuzzy sets in a single fuzzy set whose membership function captures information conveyed by the originals fuzzy sets [20]. The fuzzy aggregation operator "fuzzy or" sugested by Werners (1984) combines the maximum operator with the aritmetic mean and the combination of these two operators produces good results in decision environments, where empirical human decision performs well. 
Formally, the fuzzy-or is [21]:

$$
\begin{aligned}
& \oplus_{o r}\left(\mu_{A(x)}, \mu_{B(x)}\right)=\gamma \cdot \max \left(\mu_{A(x)}, \mu_{B(x)}\right)+\frac{(1-\gamma) \cdot\left(\mu_{A(x)}+\mu_{B(x)}\right)}{2} \\
& x \in X, \gamma \in[0,1]
\end{aligned}
$$

This operator allows compensation between the membership values of the aggregated membership values, in which the parameter $\gamma$ indicates the degree of nearness to one of the operators. In the boundaries of this operator, when $\gamma=1$ the "fuzzy or" becames the "max" operator and for $\gamma=0$ becames the arithmetic mean.

This operator was chosen for aggregating all values attributed to the factors (in the above checklists) because it allows (with an appropriate $\gamma$ ) to discriminate the inappropriate factors. The formal model for possibility of occurrence (OAP) is for each accident mode depicted in

\begin{tabular}{|c|c|c|}
\hline$O A P_{F}=\oplus_{o r} F_{f} \quad f=$ & $1 \Theta A P_{E}=\oplus_{o r} E_{e}$ & $e \Theta A P_{s} n=\oplus_{o r} S_{s}$ \\
\hline$O A P_{F o}=\oplus_{o r} F O_{r}$ & $\partial A P_{t l} . \nexists \oplus_{o r} C i_{i}$ & $O A \mathbb{P}_{\cdot H} n=\oplus_{o r} H_{h}$ \\
\hline$O A P_{M}=\oplus_{o r} M_{m}$ & $Q A A P_{F e} .:=n \bigoplus_{o r} F e_{z}$ & $z=1 \ldots n$ \\
\hline
\end{tabular}
Table 2.

Table 2: OAP Model for each accident mode. where: $F_{f} f=1 \ldots n$, are the possibility factors considered for Falls accident mode. The other accidents'modes are similarly formalized and $\oplus_{o r}$ is the fuzzy-or agregator operator. The upper limit, n, is not defined to allow the analysts to adapt the check-list itens to the specific characteristics of the site being analyzed. In the next section we discuss an illustrative example to exemplify the use of the proposed model.

\section{Illustrative Example on How to use the Possibility Accidents Model}

Let us consider the following set of factors for the accident mode that causes more deaths in

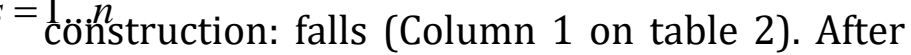
evaluation of the parameters observed in a site, $h$ the. Plisk analyst has classified each of the factors using the fuzzy classifier "adequacy", as shown in column 2 (table 2), which correspond to the membership values shown in column 3 of Table 2 .

\begin{tabular}{|c|c|c|c|}
\hline \multicolumn{2}{|c|}{ Factors-1 } & \multicolumn{2}{c|}{ Analyst decisions } \\
\cline { 2 - 4 } & $\begin{array}{c}\text { Semantic } \\
\text { term 2 }\end{array}$ & $\begin{array}{c}\text { Grade } \\
\mathbf{3}\end{array}$ & Analyst choise justification \\
\hline $\begin{array}{c}\text { To what extent are ensured that the work was properly } \\
\text { planned, appropriately supervised, and carried out in as } \\
\text { safe a way as is reasonably practicable (especially work on } \\
\text { or near fragile roof surfaces, erecting / dismantling / } \\
\text { altering scaffolding) }\end{array}$ & $\begin{array}{c}\text { Strong } \\
\text { adequate }\end{array}$ & 0.06 & Works was carefully planned. \\
\hline $\begin{array}{c}\text { If employees are exposed to the hazard of falling through } \\
\text { wall openings, scaffoldings...to what extent are the openings } \\
\text { protected? }\end{array}$ & $\begin{array}{c}\text { Very } \\
\text { adequate }\end{array}$ & 0.22 & $\begin{array}{c}\text { Are well protected and any } \\
\text { anomaly is readily solved }\end{array}$ \\
\hline $\begin{array}{c}\text { To what extent are skylight openings guarded by fixed } \\
\text { standard railings on all exposed, (or are covers capable of } \\
\text { supporting 100 kg installed)? }\end{array}$ & $\begin{array}{c}\text { Adequate } \\
\text { Are protected but the } \\
\text { reliability of the barriers can } \\
\text { be improved }\end{array}$ \\
\hline To what extent are wall openings 1,20 m or more above & Almost & 0.41 & \begin{tabular}{c} 
Mobile work platforms, with \\
\hline
\end{tabular}
\end{tabular}




\section{Ergonomics International Journal}

\begin{tabular}{|c|c|c|c|}
\hline ground properly guarded? & adequate & & $\begin{array}{l}1.50 \mathrm{~m} \text { in height have no } \\
\text { protection }\end{array}$ \\
\hline $\begin{array}{l}\text { To what extent are extension platforms outside a wall } \\
\text { properly guarded with side rails or equivalent guards? }\end{array}$ & $\begin{array}{l}\text { Low } \\
\text { adequate }\end{array}$ & 0.79 & $\begin{array}{l}\text { The robustness must be } \\
\text { improved }\end{array}$ \\
\hline $\begin{array}{l}\text { To what extent are adequate means of access to work places } \\
\text { at height? }\end{array}$ & Inadequate & 0.94 & Only by portable ladders \\
\hline $\begin{array}{c}\text { To what extent are flights of stairs with four or more risers } \\
\text { equipped with standard stair railings or handrails? }\end{array}$ & $\begin{array}{c}\text { Almost } \\
\text { adequate }\end{array}$ & 0.56 & $\begin{array}{l}\text { Railings and handrails can be } \\
\text { improved }\end{array}$ \\
\hline $\begin{array}{l}\text { To what extent proper measures to be taken so that } \\
\text { employees performing built up roofing work on low pitched } \\
\text { roofs with a ground to eave height greater than } 1,20 \mathrm{~m} \\
\text { protected from falling from the side edge of the roof? }\end{array}$ & $\begin{array}{l}\text { Low } \\
\text { adequate }\end{array}$ & 0.79 & $\begin{array}{l}\text { The protection is not ensured } \\
\text { at all stages of work, eg in the } \\
\text { assembly of the protections }\end{array}$ \\
\hline $\begin{array}{l}\text { Are employees working in a roof edge materials handling } \\
\text { area or materials storage area protected properly from } \\
\text { falling by guardrails, safety nets, or a safety belt system? }\end{array}$ & $\begin{array}{l}\text { Low } \\
\text { adequate }\end{array}$ & 0.79 & $\begin{array}{l}\text { Safety nets are not maintained } \\
\text { as regularly as appropriate }\end{array}$ \\
\hline $\begin{array}{l}\text { When employees are working from an aerial lift, to what } \\
\text { extent are body belts worn and lanyards attached properly } \\
\text { to the boom or basket? }\end{array}$ & $\begin{array}{l}\text { Low } \\
\text { adequate }\end{array}$ & 0.79 & $\begin{array}{l}\text { Workers don't know how to } \\
\text { correctly use tha body belts }\end{array}$ \\
\hline $\begin{array}{l}\text { To what extent is all protruding reinforced steel, onto or } \\
\text { into which employee could fall, guarded properly to } \\
\text { eliminate the hazard of impalement? }\end{array}$ & Adequate & 0.41 & $\begin{array}{l}\text { Protruding reinforced steel } \\
\text { are protected but it can be } \\
\text { improved }\end{array}$ \\
\hline $\begin{array}{c}\text { To what extent are aisles and passageways kept clear and in } \\
\text { good repair? }\end{array}$ & Inadequate & 0.94 & It are not kept in good repair \\
\hline $\begin{array}{c}\text { To what extent is form and scrap lumber with protruding } \\
\text { nails and all other debris kept cleared from work areas, } \\
\text { passageways, and stairs? }\end{array}$ & $\begin{array}{c}\text { Strong } \\
\text { adequate }\end{array}$ & 0.06 & Every day is clean and tidy \\
\hline $\begin{array}{c}\text { To what extent are ladders with broken or missing rungs or } \\
\text { split side rails, tagged and taken out of service? }\end{array}$ & $\begin{array}{l}\text { Very } \\
\text { adequate }\end{array}$ & 0.22 & $\begin{array}{l}\text { all ladders with rungs } \\
\text { damaged are removed from } \\
\text { service and repaired (some } \\
\text { tomes not immediately) }\end{array}$ \\
\hline $\begin{array}{l}\text { To what extent are metal ladders inspected for damage or } \\
\text { signs of corrosion? }\end{array}$ & Inadequate & 0.94 & $\begin{array}{l}\text { Ladders were found with } \\
\text { signs of corrosion }\end{array}$ \\
\hline $\begin{array}{l}\text { To what extent are portable wood ladders and metal } \\
\text { ladders adequate for their purpose, in good condition, and } \\
\text { provided with secure footing (rungs of ladders uniformly } \\
\text { spaced...)? }\end{array}$ & Adequate & 0.41 & $\begin{array}{l}\text { All ladders are certified. } \\
\text { Ladders were found with } \\
\text { signs of corrosion }\end{array}$ \\
\hline $\begin{array}{c}\text { To what extent are areas around the top and bottom of the } \\
\text { ladder kept clear? }\end{array}$ & Adequate & 0.41 & Can be improved \\
\hline $\begin{array}{l}\text { To what extent are portable ladders used at such a pitch } \\
\text { that the horizontal distance from the top bearing to the foot } \\
\text { of the ladder is about } 1 / 4 \text { of the working length of the } \\
\text { ladder? }\end{array}$ & Inadequate & 0.94 & $\begin{array}{l}\text { Workers don't know how to } \\
\text { correctly place portable } \\
\text { ladders }\end{array}$ \\
\hline $\begin{array}{l}\text { To what extent are ladders prohibited from being used in a } \\
\text { horizontal position as platforms, runways, or scaffolds? }\end{array}$ & $\begin{array}{l}\text { Low } \\
\text { adequate }\end{array}$ & 0.79 & $\begin{array}{l}\text { Is forbidden but was found an } \\
\text { old ladder to be used as a } \\
\text { platform }\end{array}$ \\
\hline $\begin{array}{c}\text { To what extent are portable ladders tied, blocked or } \\
\text { otherwise secured against movement? }\end{array}$ & $\begin{array}{c}\text { Almost } \\
\text { adequate }\end{array}$ & 0.56 & $\begin{array}{l}\text { Ladders are tied or blocked } \\
\text { when it is possible }\end{array}$ \\
\hline $\begin{array}{l}\text { To what extent are the side rails of the ladder extending } \\
\text { above the landing (at least } 90 \mathrm{~cm} \text { )? }\end{array}$ & Inadequate & 0.94 & $\begin{array}{l}\text { Is not respected this safety } \\
\text { practice }\end{array}$ \\
\hline $\begin{array}{l}\text { To what extent are stairways, runways and wall opening } \\
\text { areas well illuminated? }\end{array}$ & $\begin{array}{c}\text { Almost } \\
\text { adequate }\end{array}$ & 0.56 & $\begin{array}{c}\text { In some cases lighting can } \\
\text { cause glare }\end{array}$ \\
\hline
\end{tabular}




\section{Ergonomics International Journal}

\begin{tabular}{|c|c|c|c|}
\hline $\begin{array}{c}\text { To what extent is the working environment clean and tidy, } \\
\text { with floors and access routes kept clear of obstacles? }\end{array}$ & $\begin{array}{c}\text { Almost } \\
\text { adequate }\end{array}$ & 0.56 & $\begin{array}{c}\text { Stripping phase (and only at } \\
\text { that stage), the area of work is } \\
\text { not kept clean and tidy }\end{array}$ \\
\hline $\begin{array}{c}\text { To what extent are there adequate lighting levels } \\
\text { (functioning and position of lights to ensure all floor areas } \\
\text { are evenly lit and all potential hazards, e.g. obstructions and } \\
\text { spills can be clearly seen)? }\end{array}$ & Inadequate & 0.94 & $\begin{array}{c}\text { Were found working areas } \\
\text { with insufficient light }\end{array}$ \\
\hline
\end{tabular}

Table 3: Illustrative example of questionnaire answers for accident mode "falls".

Applying the aggregation operator "fuzzy or" with $\gamma=0,6$ (see expression 5) to all factors' ratings (see column 3, (Table 2), the resulting possibility of a work accident by fall (step 4 of $\mathrm{OAP}$ ) is $\mathrm{OAP}_{\mathrm{F}}=\bigoplus_{\text {or }}(0.06,0.22$, $0.41,0.56,0.79,0.94,0.56,0.79,0.79,0.79,0.41,0.94,0.06$, $0.22,0.94,0.41,0.41,0.94,0.79,0.56,0.94,0.56,0.56,0.94$ ) $=0.91$ ie. there is a high possibility of occurrence of an accident at work due to fall (0.91).

In this example we used $\gamma=0.6$ but this parameter of the operator can be further tuned. The possibility obtained (0.91) is the result of 2 strong adequate factors (8.33\%), 2 very adequate factors $(8.33 \%), 4$ adequate factors (16.6\%), 5 almost adequate factors (20.8\%), 5 low adequate factors $(20.8 \%)$ and 6 inadequate factors $(25 \%)$.

In practice, the obtained result means that it is absolutely necessary to implement measures of prevention or protection giving priority to the factors evaluated as inadequate, eg, adequate lighting on workplaces, adequate side rails on all ladders, proper positioning of portable ladders...

\section{Final Comments on OAP Model}

The OAP model discussed in this work presents an user-friendly method to assess the possibility of occuring accidents on construction sites. The model is based on identified factors and uses a novel fuzzy evaluation process. The OAP includes 4 main steps: (1) identification of accidents'modes; (2) definition of a checklist with factors that may affect the accidents; (3) assessment (rating) of each factor, within the identified accident'mode; (4) aggregation of factors per each mode of accident. The factors are evaluated (rated) by safety experts, from observable conditions or existing data on the construction site. The proposed fuzzy evaluation (step 4 ) is done with an specialize aggregation operator which provides and evaluation level of the adequacy of all factors.
From the literature survey, there are many other factors that may increase the risk of accidents, which are not considered in our model because we only selected the ones directly affecting the possibility of occupational accidents and that may be assessed directly on-site. Obviously our model is a work-in-progress but its versatility makes the task of adding more factors rather simple. For instance, body weight influences postural stability, and is an important risk factor for falling occupational accidents $[22,23]$. Psychotropic medications are associated with an increased risk of falls among the elderly, both psychotropic drugs and excessive alcohol consumption increase the risk of occupational and traffic accidents [24-26]. Disabilities, especially physical, sensory and cognitive disabilities, carry a high risk for occupational (specially falls) accidents [27-30].

Besides the described works there are many other important studies and identified factors that may affect the possibility of occupational accidents occurrence, such as: age, training, temporal factors, shiftwork, fatigue and sleepiness, temporary employment, foreign contractors and employees and performing tasks that was not a usual job requirement [29-46].

In summary, most of the factors just described, were not considered in this work for two main reasons: a) some characteristics of the construction make it impossible to have proactive data that can be used in their evaluation and, b) other management factors such as age, disabilities, alcohol and drugs consumption,smoking, etc, could pose ethical issues and here we will not deal with these.

Two other issues need further research to improve out OAP model. We assume all factors are independent of one another, and all have the same importance (weight), These are open issues to be investigated in the near future. 


\section{Ergonomics International Journal}

\section{Conclusion}

In this work we presented a versatile model, for determining the level of possibility of occurrence of occupational accidents. The proposed OAP model is a 4step process based on factors affecting accident modes, fuzzy ratings and specialized fuzzy operators. A checklist of questions for evaluating occupational accidents possibility was developed and pre-tested by safety experts. The presented model seems to reduce the subjectivity in assessing occupational accidents possibility, through the use of the defined check-list and the use of the linguistic variable "Adequacy" , to determine the greater or lesser possibility of each factor to contribute to the occurrence of an occupational accident. Moreover, we presented an illustrative example to better clarify the usage of the model and how to interpret the results.

We believe our proposed OAP model is quite versatile and adaptable, thus contributing to advances in determining the quality of the overall occupational risk assessment. A model for "measuring" the level of possibility of potentially hazardous events would be of undeniable value to organisations seeking to improve their understanding accident and to take preventive measures to avoid hazard environments that could lead to ocupational accidents.

As future work we plan to perform improvements on the model, such as separating percursor and immediate factors in the questions'checklist, as well as to consider other affecting factors. Moreover, and we will pursue our studies on other aspects of risk assessement in the construction industry, such as: severity factors, possibility factors, safety climate factors and ergonomic factors.

\section{Acknowledgment}

This work was funded by the Portuguese Foundation for Science and Technology, Scholarship No. SFRH/BD/39610/2007.

\section{References}

1. Phimister JR, Bier VM, Kunreuther HC (2004) Accident Precursor Analysis and Management: Reducing Technological Risk Through Diligence. National Academy Press, Washington, DC.

2. Wu W, Yang H, Chew D AS, Yang S, Gibb AGF, et al. (2010) Towards an autonomous real-time tracking system of near miss accidents on construction sites. Automation in Construction 19(2): 134-141.

3. Sawacha E, Naoum S, Fong D (1999) Factors affecting safety performance on construction sites. International Journal of Project Management 17(5): 309-315.

4. Abdelhamid TS, Everett JG (2000) Identifying root causes of construction accidents. Journal of Construction Engineering and Management 126(1): 52-60.

5. Tam CM, Zeng SX, Deng ZM (2004) Identifying elements of poor construction safety management in China. Safety Science 42(7): 569-586.

6. Mitropoulos P, Abdelhamid TS, Howell GA (2005) Systems model of construction accident causation. Journal of Construction Engineering and Management 131(7): 816-825.

7. Choudhry RM, Fang D (2008) Why operatives engage in unsafe work behavior: investigating factors on construction sites. Safety Science 46(4): 566-584.

8. Aven T (2003) Foundations of Risk Analysis. John Wiley \& Sons, Chichester.

9. Cuny X, Lejeune M (1999) Occupational risks and the value and modeling of a measurement of severity. Safety Science 31(3): 213-229.

10. Zadeh LA (1965) Fuzzy sets. Information and Control 8(3): 338-353.

11. Ru WG, Eloff J HP (1996) Risk analysis modelling with the use of fuzzy logic. Computers and Security 15(3): 239-248.

12. Zadeh LA (1975) The concept of a linguistic variable and its application to approximate reasoning-part I. Information Sciences 8(3): 199-249.

13. Zadeh LA (1978) PRUF-a meaning representation language for natural languages. International Journal of Man-Machine Studies 10(4): 395-460.

14. Zadeh LA (1983) Linguistic variables, approximate reasoning and dispositions. Medical Informatics 8(3): 173-186.

15. Pender S (2001) Managing incomplete knowledge: Why risk management is not sufficient. International Journal of Project Management 19(2): 79-87. 
16. Jeong BY (1998) Occupational deaths and injuries in the construction industry. Applied Ergonomics 29(5): 355-360.

17. Müngen U, Gürcanli GE (2005) Fatal traffic accidents in the Turkish construction industry. Safety Science 43(5,6): 299-322.

18. MOSH (2011) Checklist for Self-Inspection. Maryland Occupational Safety and Health.

19. Simões-Marques M (1999) System Fuzzy Support Decision for Priorities, Equipment Repair and Resources Allocation of Management in Ships in Combat Situation. M/Sc Dissertation, Universidade Nova de Lisboa/Faculdade de Ciências e Tecnologia, DepEng Informática.

20. Pedrycz W, Gomide F (2007) Fuzzy systems engineering toward human-centric computing. Jonh Wiley \& Sons, Hoboken, New Jersey.

21. Zimmerman HJ (1993) Fuzzy Set Theory and its Applications. Kluwer Academic Publishers, London, pp: 399.

22. Gauchard C, Chau N, Touron C, Benamghar L, Dehaene $\mathrm{D}$, et al. (2003) Individual characteristics in occupational accidents due to imbalance: a casecontrol study in the employees of a railway company. Occupational \& Environmental Medicine 60(5): 330335.

23. Hue O, Simoneau M, Marcotte J, Berrigan F, Dore J, et al. (2007) Body weight is a strong predictor of postural stability. Gait \& Posture 26(1): 32-38.

24. Ray WA (1992) Psychotropic drugs and injuries among the elderly: a review. Journal of clinical psychopharmacology 12(6): 386-396.

25. Landi F, Onder G, Cesari M, Barillaro C, Russo A, et al. (2005) Psychotropic medications and risk for falls among community-dwelling frail older people: an observational study. Journal of Gerontology 60(5): 622-626.

26. Mura P, Kintz P, Ludes B, Gaulier JM, Marquet P, et al. (2003) Comparison of the prevalence of alcohol, cannabis and other drugs between 900 injured drivers and 900 control subjects: results of a French collaborative study. Forensic Science International 133(1-2): 79-85.
27. Zwerling C, Whitten PS, Davis CS, Sprince NL (1997) Occupational injuries among workers with disabilities: the national Health Interview Survey, 1985-1994. Journal of the American Medical Association 278(24): 2163-2166.

28. Zwerling C, Sprince NL, Davis CS, Whitten PS, Wallace RR, et al. (1998) Occupational injuries among older workers with disabilities: a prospective cohort study of the health and retirement survey, 1992 to 1994. American journal of public health 88(11): 1691-1695.

29. Chau N, Mur JM, Touron C, Benamghar L, Dehaene D (2004) Correlates of occupational injuries for various jobs in railway workers: a case-control study. Journal of Occupational Health 46(4): 272-280.

30. Chau N, Mur JM, Benamghar L, Siegfried C, Dangelzer $\mathrm{JL}$, et al. (2004) Relationships between certain individual characteristics and occupational accidents for various jobs in the construction industry: a casecontrol study. American Journal of Industrial Medicine 45(1): 84-92.

31. Hertz RP, Emmett EA (1986) Risk Factors for Occupational Hand Injury. Journal of Occupational and Environmental Medicine 28(1): 36-41.

32. Hallsten L (1990) Time and accident a register study. Journal of Occupational Accidents 12: 187-188.

33. Jimeno JF, Toharia L (1993) The effects of fixed term employment on wages: theory and evidence from Spain. Investigaciones Economicas 17(3): 475-494.

34. Jimeno JF, Toharia L (1996) Effort, absenteeism and fixed term employment contracts. Revista Española de Economia 13(1): 105-119.

35. Dinges DF (1995) An overview of sleepiness and accidents. Journal of Sleep Research 4(2): 4-14.

36. Spurgeon A, Harrington JM, Cooper CL (1997) Health and safety problems associated with long working hours: a review of the current position. Occupational and Environmental Medicine 54(6): 367-375.

37. Nag PK, Patel VG (1998) Work accidents among shiftworkers in industry. International Journal of Industrial Ergonomics 21(3,4): 275-281.

38. Hamermesh D (1999) Changing inequality in markets for workplace disamenities. Quarterly Journal of Economics 114(4): 1085-1123. 
39. Nakata A, Ikeda T, Takahashi M, Haratani T, Hojou M, et al. (2006) Non-fatal occupational injury among active and passive smokers in small- and mediumscale manufacturing enterprises in Japan. Social Science \& Medicine 63(9): 2452-2463.

40. Fabiano B, Curro F, Reverberi A, Pastorino R (2008) A statistical study on temporary work and occupational accidents: Specific risk factors and risk management strategies. Safety Science 46(3): 535-544.

41. Khlat M, Ravaud JF, Brouard N, Chau N (2008) Occupational disparities in accidents and roles of lifestyle factors and disabilities: a population-based study in north-eastern France. Public Health 122(8): 771-783.
42. Williamson A, Lombardi D, Folkard S, Stutts J, Courtney T, et al. (2011) The link between fatigue and safety. Accident Analysis and Prevention 43(2): 498515.

43. Aneziris ON, Papazoglou IA, Baksteen H, Mud M, Ale BJ, et al. (2008) Quantified risk assessment for fall from height. Safety Science 46(2): 198-220.

44. Booth AL, Francesconi M, Frank J (2002) Temporary jobs: stepping stones or dead ends?. Economic Journal 112(480): 189-213.

45. Knudson DV (2007) Fundamentals of biomechanics, $2^{\text {nd }}($ Edn.), Springer, Spring street, New York.

46. Ross TJ (1995) Fuzzy Logic with Engineering Applications. McGraw-Hill, New York. 